\title{
Bladder Non-Invasive Papillary Urothelial Carcinoma, High Grade
}

National Cancer Institute

\section{Source}

National Cancer Institute. Bladder Non-Invasive Papillary Urothelial Carcinoma, High

Grade. NCI Thesaurus. Code C27876.

Bladder non-invasive papillary urothelial carcinoma characterized by marked architectural and cytologic abnormalities and frequent mitotic figures (at all levels of the urothelium). 